\title{
Autoinflammatory syndromes as causes of fever of unknown origin
}

\author{
Author: Helen J Lachmann ${ }^{A}$
}

The systemic autoinflammatory syndromes often present with recurrent fevers. They have proved exceptionally informative about the innate immune system. Although extremely rare, they are important to recognise, as many can now be completely controlled by long-term drug therapies. Diagnosis relies on clinical suspicion followed by genetic testing.

\section{Introduction}

The systemic autoinflammatory syndromes (SAIDs) are disorders of innate immunity which cause recurrent attacks of systemic inflammation usually with fever. There are both genetic and acquired forms. SAIDs can present at almost any age, although many onset in early childhood, $10 \%$ of patients will have their first symptoms after the age of 30 years. ${ }^{1}$ Although these are extremely rare conditions, they are of disproportionate importance because untreated they can result in prolonged invasive investigations and unnecessary surgery, as well as severely impaired quality of life. Importantly, recent advances have radically improved the ability to diagnose and treat them. In most of these conditions, diagnosis involves recognition of suspicious clinical features followed by confirmatory genetic testing for the inherited forms (Table 1). ${ }^{2}$

\section{The inherited autoinflammatory syndromes}

\section{Familial Mediterranean fever}

Familial Mediterranean fever (FMF) is the most common SAID and was first described in 1945; although the name FMF was coined in the 1950s. It is caused by gain of function mutations in the Mediterranean fever (MEFV) gene, and 80\% will have a mutation in both alleles. Diagnosis is supported by DNA analysis but remains clinical, centring on a history of recurrent self-limiting attacks of fever and serositis that respond to prophylactic colchicine. ${ }^{3,4} \mathrm{FMF}$ is commonest in Middle Eastern populations with a prevalence of up to $1 / 250$ among Sephardic Jews and 1/1,000 in Turkish individuals, however incidence occurs worldwide. Genders are equally affected and

Author: Areader in medicine/honorary consultant nephrologist, UK National Amyloidosis Centre, London, UK symptoms usually start in childhood. As a recessive disease there is often no family history. Attacks may be precipitated by minor physical or emotional stress or the menstrual cycle. Fever and serositis are the cardinal features of attacks and resolve within 12 to 72 hours. Severe peritonitic pain is seen in $85 \%$ of attacks and $40 \%$ of patients will have had surgery for a presumed acute abdomen. Unilateral pleuritic pain occurs in $15 \%$ of attacks but joint involvement is rarer. An erysipelas-like rash occurs in less than $20 \%$ of cases but is highly characteristic. Attacks are always accompanied by an intense acute phase response. Investigations may be required to exclude other diagnoses but imaging during attacks is usually unrewarding. Untreated disease is not only extremely symptomatic, interfering with education and employment, but also carries an up to $60 \%$ risk of death from AA amyloidosis and renal failure.

Analgesia is required during acute attacks, but the mainstay of management is long-term prophylaxis with low-dose colchicine. This has been used since the early 1970s and has transformed the outlook of the disease. Continuous treatment with colchicine at a dose of 1-2 mg daily in adults prevents or substantially reduces symptoms of FMF in at least $95 \%$ and almost completely

\section{Key points}

Systemic autoinflammatory syndromes are rare disorders of innate immunity.

They provide novel insights into the importance and regulation of innate immunity in humans.

The inherited forms usually manifest in infancy or childhood but diagnosis is often delayed until adulthood.

Untreated disease carries risks of severe complications, including renal failure from AA amyloidosis and chronic damage particularly to joints and the central nervous system.

There are now specific and highly effective treatments for many of these rare syndromes.

KEYWORDS: Autoinflammation, systemic autoinflammatory syndromes, FMF, TRAPS, MKD, CAPS, PFAPA, Schnitzler's syndrome, IL-1 
Table 1. Characteristics of the commonest SAIDs.

\begin{tabular}{|c|c|c|c|c|c|c|}
\hline & FMF & TRAPS & MKD & CAPS & PFAPA & Schnitzler's \\
\hline Inheritance & $\begin{array}{l}\text { Autosomal } \\
\text { recessive }\end{array}$ & $\begin{array}{l}\text { Autosomal } \\
\text { dominant }\end{array}$ & $\begin{array}{l}\text { Autosomal } \\
\text { recessive }\end{array}$ & $\begin{array}{l}\text { Autosomal } \\
\text { dominant }\end{array}$ & $\begin{array}{l}\text { Presumed } \\
\text { polygenetic }\end{array}$ & $\begin{array}{l}\text { Acquired - } \\
\text { related to IgM } \\
\text { paraprotein }\end{array}$ \\
\hline Ethnicity & $\begin{array}{l}\text { Eastern } \\
\text { Mediterranean }\end{array}$ & $\begin{array}{l}\text { European } \\
\text { dominance } \\
\text { may reflect } \\
\text { ascertainment } \\
\text { bias }\end{array}$ & $\begin{array}{l}\text { Mainly } \\
\text { northwestern } \\
\text { European }\end{array}$ & $\begin{array}{l}\text { European } \\
\text { dominance } \\
\text { may reflect } \\
\text { ascertainment } \\
\text { bias }\end{array}$ & $\begin{array}{l}\text { European } \\
\text { dominance may } \\
\text { reflect } \\
\text { ascertainment } \\
\text { bias }\end{array}$ & $\begin{array}{l}\text { European } \\
\text { dominance } \\
\text { may reflect } \\
\text { ascertainment } \\
\text { bias }\end{array}$ \\
\hline Chromosome & $16 p 13$ & $12 \mathrm{p} 13$ & $12 q 24$ & $1 q 44$ & & \\
\hline Gene & MEVF & TNFRSF1A & $M V K$ & NLRP3 & & \\
\hline Affected protein & Pyrin & $\begin{array}{l}55 \mathrm{kDa} \text { TNF } \\
\text { receptor }\end{array}$ & $\begin{array}{l}\text { Mevalonate } \\
\text { kinase }\end{array}$ & Cryopyrin & & \\
\hline Typical duration & $12-72$ hours & $>7$ days & 3-7 days & Daily & 2-5 days & Daily \\
\hline Skin manifestation & $\begin{array}{l}\text { Erysipelas-like on } \\
\text { the lower legs/feet }\end{array}$ & Migratory rash & $\begin{array}{l}\text { Maculopapular } \\
\text { rash }\end{array}$ & Urticarial rash & & Urticarial rash \\
\hline $\begin{array}{l}\text { Classical clinical } \\
\text { signs }\end{array}$ & $\begin{array}{l}\text { Peritonitic signs, } \\
\text { pleuritis }\end{array}$ & $\begin{array}{l}\text { Periorbital } \\
\text { oedema, } \\
\text { myalgia, } \\
\text { conjunctivitis }\end{array}$ & $\begin{array}{l}\text { Triggered by } \\
\text { vaccination }\end{array}$ & $\begin{array}{l}\text { Hearing loss, } \\
\text { aseptic } \\
\text { meningitis, red } \\
\text { eyes }\end{array}$ & $\begin{array}{l}\text { Pharyngitis, } \\
\text { apthous ulcers, } \\
\text { cervical } \\
\text { lymphadenopathy }\end{array}$ & \\
\hline $\begin{array}{l}\text { Typical age at } \\
\text { onset }\end{array}$ & $90 \%<20$ years & $\begin{array}{l}\text { Variable (mean } \\
3 \text { years) }\end{array}$ & $<1$ year & $<1$ year & Aged $<5$ years & Sixth decade \\
\hline $\begin{array}{l}\text { Amyloidosis (risk in } \\
\text { untreated disease) }\end{array}$ & $25-60 \%$ & $10-20 \%$ & Unusual & $25 \%$ & None to date & $\begin{array}{l}\text { Few case } \\
\text { reports }\end{array}$ \\
\hline
\end{tabular}

eliminates the risk of AA amyloidosis. As a result of widespread use of colchicine, life expectancy in FMF now matches that of the healthy population in Turkey and Israel. ${ }^{5}$ Despite theoretical concerns, there is no evidence that colchicine causes infertility or birth defects. ${ }^{6,7}$ Colchicine is licensed in the US for the treatment of FMF from the age of 4 years.

\section{Tumour necrosis factor receptor associated periodic syndrome}

Tumour necrosis factor receptor associated periodic syndrome (TRAPS) is an autosomal dominant disease associated with mutations in the gene for tumour necrosis factor receptor superfamily 1A (TNFRSF1A) and has an estimated prevalence in the UK of $1-2 /$ million. The mechanisms by which heterozygous TNFRSF1A mutations cause inflammatory disease remain unclear; cell surface interactions with TNF seem to be much less relevant than intracellular stress responses to misfolded proteins. ${ }^{8}$

TRAPS has been reported in many ethnicities and only $60 \%$ of patients report a family history. ${ }^{9}$ Mean age at first symptoms is 7 years. Febrile episodes typically last more than 10 days and symptoms are near continuous in a third of patients. The clinical picture varies: more than $95 \%$ of patients experience fever, and $90 \%$ have arthralgia or myalgia that typically follows a centripetal migratory path; abdominal pain occurs in $75 \%$, and variable rashes are seen in $60 \%$ of patients. Other features include headache, pleuritic pain, lymphadenopathy, periorbital oedema and conjunctivitis. Symptoms are universally accompanied by a marked acute-phase response, and genetic testing is central to diagnosis.

Acute attacks respond to high-dose corticosteroids but in severe disease the cumulative doses required are toxic. Conventional steroid sparing immunosuppressant agents are of no benefit and specific anticytokine agents are currently the only effective long-term treatment. Etanercept has been used for more than a decade and is effective in some patients, although responses are frequently partial and wane over time. Interleukin (IL)-1 blockade appears the most effective treatment and is now the maintenance treatment of choice. ${ }^{1}$

\section{Mevalonate kinase deficiency}

Mevalonate kinase deficiency (MKD), also known as hyperimmunoglobulin $\mathrm{D}$ and periodic fever syndrome, is a recessive disease caused by mutations in the mevalonate kinase $(M V K)$ gene which encodes the enzyme after HMG CoA reductase in the cholesterol synthesis pathway. ${ }^{10}$ Most $M V K$ mutations reduce enzyme activity by more than $90 \%$. It is not yet known how MVK deficiency causes inflammation, though 
a relative deficiency of substrate for the geranylgeranyl pathway now seems most likely.

MKD is extremely rare and is predominantly found in northwestern Europe, probably through a founder effect. Nonetheless it has been reported in many other ethnic groups. The disease usually presents in the first year of life. Attacks are irregular, typically lasting four to seven days, and are characteristically provoked by vaccination, perhaps triggered by a reduction in MVK enzyme associated with increased body temperature. Typical features are fever, cervical lymphadenopathy and abdominal pain with vomiting and diarrhoea. Headache, red eye, arthralgia, erythematous rash and aphthous ulcers are also common. In milder cases, symptoms may partially ameliorate in adult life.

Diagnosis was initially thought to be supported by a high serum IgD concentration but this is neither specific nor universal. More accessibly, serum IgA concentration is elevated in $80 \%$. Attacks are accompanied by an acute-phase response, and transient mevalonic aciduria. A mutation in both alleles of the $M V K$ gene can be identified in most patients.

Symptomatic treatment, includes non-steroidal antiinflammatory drugs, and excellent responses to IL-1 inhibitors, anti-TNF agents and IL- 6 blockade have all been reported. ${ }^{1}$

\section{Cryopyrin-associated periodic syndrome}

Cryopyrin-associated periodic syndrome (CAPS) is an autosomal dominant disease associated with mutations in NOD-like receptor family, pyrin domain containing 3 (NLRP3), with an estimated prevalence of $1-2 /$ million. Approximately three quarters of patients with milder disease give a family history of similar symptoms. ${ }^{11,12}$ The most severe disease, known as chronic infantile neurological cutaneous and articular syndrome (CINCA) or neonatal onset multisystem inflammatory disorder (NOMID), is usually due to de novo mutation. NLPR3 is a key component of the inflammasone, an intracellular platform which regulates the production of IL-1 beta. Mutations result in constitutive overexpression of IL-1 beta, a major pro-inflammatory cytokine.

Onset of disease is usually in early infancy, often from birth. At its mildest, CAPS causes recurrent episodes of cold-induced fever, arthralgia, inflamed red eyes and urticarial rash. Mid-spectrum disease is characterised by daily symptoms, progressive sensorineural deafness in $40 \%$, and a high incidence of AA amyloidosis. At its most severe end the disease includes bony overgrowth, particularly in the skull and knees, and chronic aseptic meningitis with developmental retardation and impaired hearing and vision.

Clinical disease is accompanied by an acute-phase response, leukocytosis, thrombocytosis and anaemia. When deafness occurs, it tends to progress in a step-wise fashion through childhood. ${ }^{13}$

Inhibition of IL-1 produces rapid clinical and serological remission in CAPS. ${ }^{14-16}$ It is hoped that early anti-IL-1 therapy may prevent long-term complications, not only of AA amyloidosis in adults but potentially progressive neurological and physical disability in children. Three separate anti IL-1 agents (anakinra, rilonacept and canakinumab) are licensed for long-term treatment of CAPS.

\section{Autoinflammatory diseases of unknown aetiology}

Periodic fever, aphthous stomatitis, pharyngitis and adenitis

Periodic fever, aphthous stomatitis, pharyngitis and adenitis (PFAPA) was first described in 1987. The diagnosis is suggested by recurrent fever of early onset and one or more of the following associated symptoms: oral aphthous ulcers, cervical lymphadenopathy or pharyngitis, in the absence of recurrent upper respiratory tract infections or cyclic neutropenia. ${ }^{17,18}$ Characteristically the children are entirely well between attacks. In a large series, median age at presentation was 2.5 years and $83 \%$ presented before their fifth birthday with a slight male preponderance. During attacks the acute phase response is often strikingly elevated. Often the strongest diagnostic pointer is the extreme regularity of attacks and the rapid response to a small dose of corticosteroids. The aetiology of the syndrome is poorly understood but overproduction of IL-1 by monocytes is a candidate mechanism. ${ }^{19}$ In general, the prognosis is good and many children will outgrow their symptoms within a decade.

\section{Schnitzler's syndrome}

Schnitzler's syndrome is a disease of adults and was first reported in 1974. It is characterised by chronic urticariallike rashes, a monoclonal immunoglobulin M gammopathy and systemic inflammation usually presenting as fever. ${ }^{20}$ The median age at onset is 51 years. There is a slight male preponderance and the majority of reported cases to date are Caucasian. The monoclonal protein appears central to the pathogenesis, although the mechanism remains unclear and it is apparently unrelated to its abundance. Approximately $15 \%$ of cases will eventually progress to a haematological malignancy. Chemotherapy has been used in the past but does not appear to relieve the syndrome and should only be used for conventional haematological indications. The treatment of choice of Schnitzler's is now IL-1 blockade. This has been reported to completely abolish symptoms, although it has no effect on the paraprotein concentration. ${ }^{21}$ The diagnosis is rare but important, as correct identification transforms quality of life and prevents exposure of, often elderly, patients to highdose corticosteroids which are only partially effective and often poorly tolerated.

\section{Conclusions}

In conclusion, the SAIDs can present with fever of unknown origin. Although they are all very infrequent, and most clinicians will never have encountered a case, they are important to consider. There is much ongoing work into their underlying pathogenesis, and this has already translated into significant advances in both diagnosis and treatment. The availability of colchicine and specific cytokine blockers has transformed the quality of life and prognosis for patients with these diseases to a remarkable extent.

\section{References}

1 Toplak N, Frenkel J, Ozen S et al. An international registry on autoinflammatory diseases: the Eurofever experience. Ann Rheum Dis 2012;71:1177-82. 
2 Kallinich T, Gattorno M, Grattan CE et al. Unexplained recurrent fever: when is autoinflammation the explanation? Allergy 2013;68:285-96.

3 Livneh A, Langevitz P, Zemer D et al. Criteria for the diagnosis of familial Mediterranean fever. Arthritis Rheum 1997;40:1879-85.

4 Giancane G, Ter Haar N, Wulffraat N et al. Evidence-based recommendations for genetic diagnosis of familial Mediterranean fever. Ann Rheum Dis 2015;74:635-41.

5 Twig G, Livneh A, Vivante A et al. Mortality risk factors associated with familial Mediterranean fever among a cohort of 1.25 million adolescents. Ann Rheum Dis 2014;73:704-9.

6 Ben-Chetrit E, Ben-Chetrit A, Berkun Y, Ben-Chetrit E. Pregnancy outcomes in women with familial Mediterranean fever receiving colchicine: is amniocentesis justified? Arthritis Care Res (Hoboken) 2010;62:143-8.

7 Yanmaz MN, Ozcan AJ, Savan K. The impact of familial Mediterranean fever on reproductive system. Ann Rheum Dis 2003;62:916-9.

8 Bachetti T, Chiesa S, Castagnola P et al. Autophagy contributes to inflammation in patients with TNFR-associated periodic syndrome (TRAPS). Ann Rheum Dis 2013;72:1044-52.

9 Lachmann H, Papa R, Gerhold K et al. The phenotype of TNF receptor-associated autoinflammatory syndrome (TRAPS) at presentation: a series of 158 cases from the Eurofever/EUROTRAPS international registry. Ann Rheum Dis 2014;73:2160-7.

10 Esposito S, Ascolese B, Senatore L et al. Current advances in the understanding and treatment of mevalonate kinase deficiency. Int $J$ Immunopathol Pharmacol 2014;27:491-8.

11 Levy R, Gérard L, Kuemmerle-Deschner J et al. Phenotypic and genotypic characteristics of cryopyrin-associated periodic syndrome: a series of 136 patients from the Eurofever Registry. Ann Rheum Dis 2014 Jul 18, epub ahead of print.

12 Leslie KS, Lachmann HJ, Bruning E et al. Phenotype, genotype, and sustained response to anakinra in 22 patients with autoinflammatory disease associated with CIAS-1/NALP3 mutations. Arch Dermatol 2006;142:1591-7.
13 Kuemmerle-Deschner J, Koitschev A et al. Hearing loss in MuckleWells syndrome. Arthritis Rheum 2013;65:824-31.

14 Lachmann HJ, Kone-Paut I, Kuemmerle-Deschner JB et al. Use of canakinumab in the cryopyrin-associated periodic syndrome. $N$ Engl J Med 2009;360:2416-25.

15 Goldbach-Mansky R, Dailey NJ et al. Neonatal-onset multisystem inflammatory disease responsive to interleukin-1b inhibition. $N$ Engl J Med 2006;355:581-92.

16 Hoffman HM, Throne ML, Amar NJ et al. Efficacy and safety of rilonacept (interleukin-1 trap) in patients with cryopyrin-associated periodic syndromes: results from two sequential placebo-controlled studies. Arthritis Rheum 2008;58:2443-52.

17 Marshall GS, Edwards KM, Butler J, Lawton AR. Syndrome of periodic fever, pharyngitis, and aphthous stomatitis. J Pediatr 1987;110:43-6.

18 Hofer M, Pillet $\mathrm{P}$, Cochard $\mathrm{M}$ et al. International periodic fever, aphthous stomatitis, pharyngitis, cervical adenitis syndrome cohort: description of distinct phenotypes in 301 patients. Rheumatology 2014;53:1125-9.

19 Kolly L, Busso N, von Scheven-Gete A et al. Periodic fever, aphthous stomatitis, pharyngitis, cervical adenitis syndrome is linked to dysregulated monocyte IL- $1 \beta$ production. J Allergy Clin Immunol 2013;131:1635-43.

20 Simon A, Asli B, Braun-Falco M et al. Schnitzler's syndrome: diagnosis, treatment, and follow-up. Allergy 2013;68:562-8.

21 Néel A, Henry B, Barbarot S et al. Long-term effectiveness and safety of interleukin-1 receptor antagonist (anakinra) in Schnitzler's syndrome: a French multicenter study. Autoimmunity Rev 2014;13:1035-41.

Address for correspondence: Dr HJ Lachmann, UK National Amyloidosis Centre, UCL Division of Medicine, Royal Free Campus, Rowland Hill Street, London NW3 2PF, UK. Email: h.lachmann@ucl.ac.uk 